\title{
Nicotine suppresses apoptosis by regulating a7nAChR/Prx1 axis in oral precancerous lesions
}

\author{
Chunxiao Wang ${ }^{1}$, Wenwen Niu${ }^{1}$, Hui Chen ${ }^{1}$, Ni Shi ${ }^{2}$, Dian $\mathrm{He}^{3}$, Min Zhang ${ }^{1}$, Lihua \\ $\mathbf{G e}^{1}$, Zhenchuan Tian ${ }^{1}$, Moci $\mathbf{Q i}^{1}{ }^{1}$, Tong Chen ${ }^{2, *}$ and Xiaofei Tang ${ }^{1, *}$ \\ ${ }^{1}$ Division of Oral Pathology, Beijing Institute of Dental Research, Beijing Key Laboratory, Beijing Stomatological Hospital \& \\ School of Stomatology, Capital Medical University, Beijing, China \\ ${ }^{2}$ Division of Medical Oncology, Department of Internal Medicine, The Arthur G. James Cancer Hospital and Richard J. Solove \\ Research Institute, The Ohio State University, Columbus, $\mathrm{OH}$, USA \\ ${ }^{3}$ Department of Epidemiology and Health Statistics, School of Public Health, Capital Medical University, Beijing, China \\ *These authors have contributed equally to this work \\ Correspondence to: Xiaofei Tang, email: xftang10@ccmu.edu.cn
}

Tong Chen, email: tong.chen@osumc.edu

Keywords: oral precancerous lesion, Prxl, nicotine, a3nAChR, a7nAChR

Received: February 22, $2017 \quad$ Accepted: July 29, $2017 \quad$ Published: August 24, 2017

Copyright: Wang et al. This is an open-access article distributed under the terms of the Creative Commons Attribution License 3.0 (CC BY 3.0), which permits unrestricted use, distribution, and reproduction in any medium, provided the original author and source are credited.

\section{ABSTRACT}

Nicotine, a tumor promoter in tobacco, can increase Peroxiredoxin (Prx1) and nicotinic acetylcholine receptors (nAChRs) in oral squamous cell carcinoma (OSCC). In the present study, we investigate the effects of nicotine in oral precancerous lesions focusing on apoptosis and nAChR/Prx1 signaling. We detected expression of Prx1, a3nAChR, a7nAChR, phosphorylation of mitogen-activated protein kinases (MAPK) and apoptosis in dysplastic oral keratinocyte (DOK) cells as well as in 4-nitroquinoline 1-oxide (4NQO) or 4NQO + nicotine - induced oral precancerous lesions in Prx1 wildtype $\left(\mathrm{Prx1}^{+/+}\right)$and Prx1 knockdown (Prx1 $\left.{ }^{+/-}\right)$mice. In DOK cells, Prx1 knockdown and blocking a7nAChR activated apoptosis, and nicotine increased the expression of Prx1, a3nAChR and a7nAChR, and inhibited MAPK activation. Moreover, nicotine suppressed apoptosis depending on Prx1 and a7nAChR in DOK cells. In animal bioassay, nicotine and Prx1 promoted growth of 4NQO-induced precancerous lesions in mouse tongue. 4NQO plus nicotine suppressed MAPK activation in Prx1 wild-type mice but not in Prx1 knockdown mice. Our data demonstrate that nicotine inhibits cell apoptosis and promotes the growth of oral precancerous lesions via regulating a7nAChR/Prx1 during carcinogenesis of OSCC.

\section{INTRODUCTION}

Oral cancer is the sixth most common malignant tumors worldwide, with more than $90 \%$ of oral cancers in squamous cell carcinoma type [1]. There are approximate 500,000 new cases diagnosed with oral squamous cell carcinoma (OSCC) annually and more than 250,000 cases died every year [2]. The overall 5-year survival rate of oral cancer remains around $50 \%$ despite the advances of radiotherapy and chemotherapy in recent decades [3]. Oral leukoplakia (OLK) is one of the most prevalent oral precancerous lesions of OSCC and increases the risk of
OSCC development at a malignant transformation rate of $0.13-17.5 \%[4,5]$. Therefore, it is critical to monitor OLK development and reduce the prevalence of OSCC through reversal of OLK by clinical interventions.

Etiologically, tobacco is one of the most important risk factors in OLK pathogenesis [5]. Nicotine, a tumor promoter in tobacco, contributes to tumorigenesis mainly by promoting growth and survival of mutated cancer cells and protecting them from apoptosis by creating a tumor favorable environment [6]. In-vitro studies showed that nicotine inhibits apoptosis in oral cancer [7,8]. Nicotinic acetylcholine receptors (nAChRs) play an important role 
in nicotine induced tumorigenesis [9]. nAChRs ligands gate across the plasma membrane ion channel receptors and are composed of various subunits of homologous or heterologous polymers [9]. nAChR subtypes $\alpha 2, \alpha 3, \alpha 4$, $\alpha 5, \alpha 7$ and $\alpha 9$ are identified in oral epithelial cells [10]. The activation of $\alpha 3, \alpha 4, \alpha 7$ and $\alpha 9$ nAChR can produce a combination effect of growth-promoting and anti-apoptotic signals [11]. $\alpha 7 \mathrm{nAChR}$ is the main subtype receptor of tobacco products [12]. The alteration of $\alpha 7 \mathrm{nAChR}$ accompanied by induced epidermal growth factor (EGF), phosphatidylinositol-4,5-bisphosphate 3-kinase (PI3K), cyclin D1, extracellular signal-regulated kinase (ERK1/2) and inhibition of mitochondrial permeability transition pore (mPTP) opening facilitates tumor promotion and progression [13-15]. Studies show that long-term use of nicotine enhances cancer cell migration and invasion with morphological alterations, and inhibition of $\alpha 7 \mathrm{nAChR}$ may provide a feasible approach for preventing the progression of head and neck cancer [16]. $\alpha 3 \mathrm{nAChR}$ is another key acetylcholine receptor in oral epithelial cells. Studies suggest that $\alpha 3 \mathrm{nAChR}$ gene silencing and $\alpha 3 \mathrm{nAChR}$ antagonist inhibit nicotine-induced cell proliferation in oral gingival epithelial cells [17].
In our previous studies, we observed an overexpression of Peroxiredoxin 1 (Prx1), $\alpha 3$ and $\alpha 7 \mathrm{nAChRs}$ in SCC15 cells exposed to nicotine [18]. We also found that Prx1 was involved in OLK pathogenesis by providing resistance against extracellular damages from oxidative stress via inhibition of apoptosis signalregulating kinase 1 (ASK1) [19]. However, the data about the functional role of Prx1 in nicotine-related oral precancerous lesions are limited. In the current study, we assessed nAChR/Prx 1 axis in vitro and in 4-nitroquinoline 1-oxide (4NQO) or 4NQO + Nicotine - induced oral precancerous lesions in wild-type $\left(\operatorname{Prx} 1^{+/+}\right)$and $\operatorname{Prx} 1$ knockdown $\left(\operatorname{Prx} 1^{+/}\right)$mice.

\section{RESULTS}

\section{Nicotine upregulates the expression of Prx1, $\alpha 3 n A C h R$ and $\alpha 7 n A C h R$ in vitro}

In oral precancerous cell line DOK cells, nicotine significantly increased the mRNA expression of Prx1, $\alpha 3 \mathrm{nAChR}$ and $\alpha 7 \mathrm{nAChR}$ when compared to control cells $(P<0.05$, Figure 1A). Similar results were observed in
A

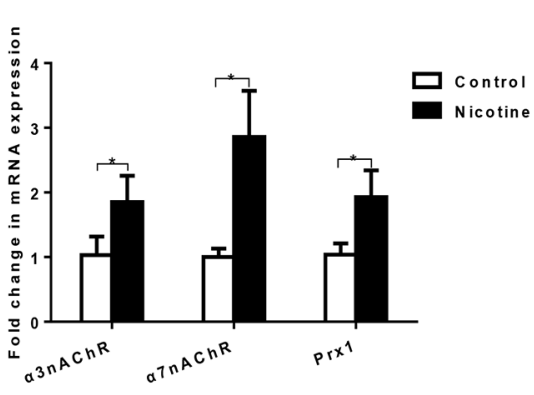

B

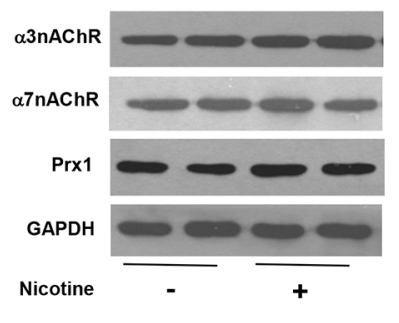

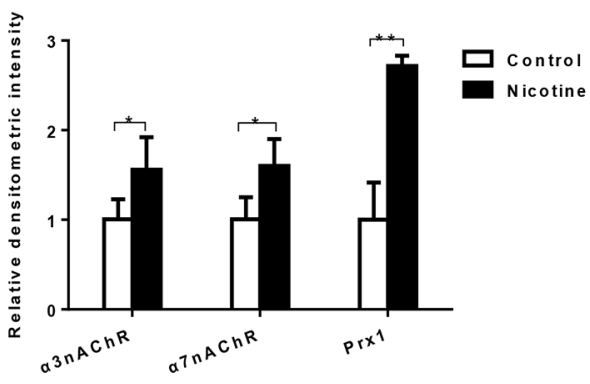

C

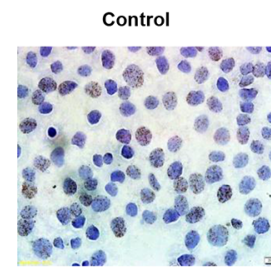

D

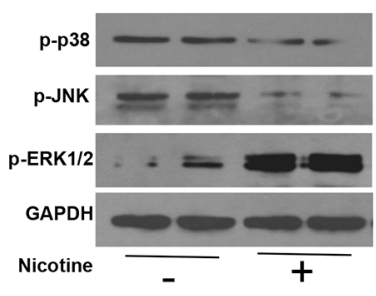

Control + nicotine
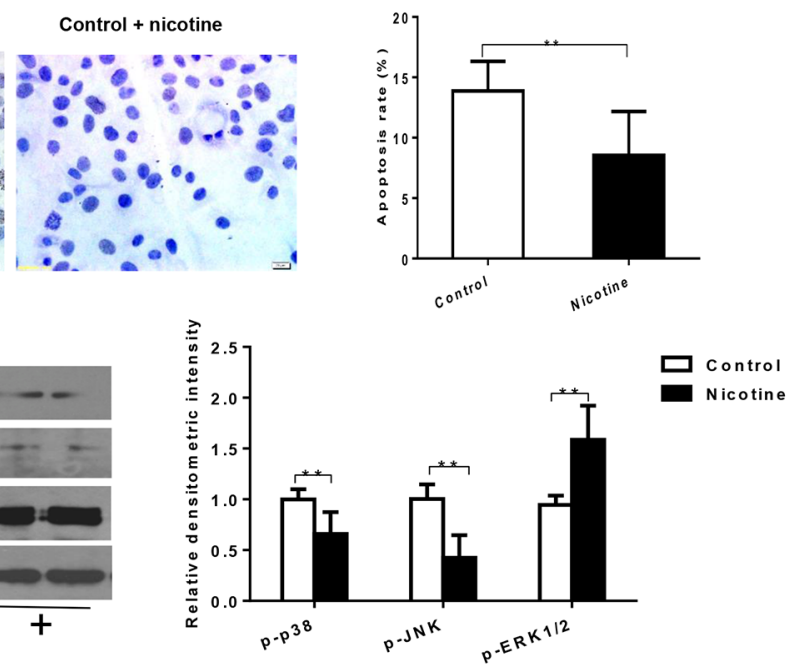

Figure 1: Nicotine increases expression of $\alpha 3 \mathrm{nAChR}, \alpha 7 \mathrm{nAChR}$ and Prx1, and inhibits apoptosis in DOK cells. (A) mRNA expression of $\alpha 3 \mathrm{nAChR}, \alpha 7 \mathrm{nAChR}$ and Prx1; (B) protein expression of $\alpha 3 \mathrm{nAChR}, \alpha 7 \mathrm{nAChR}$ and Prx1; (C) apoptosis rate detected by TUNEL; and (D) phosphorylation of p38, JNK and ERK1/2. The values are expressed as mean; bars, \pm SE. $* P<0.05 ; * * P<0.01$. 
protein expression of Prx1 $(P<0.01), \alpha 3 n A C h R$ and $\alpha 7$ nAChR $(P<0.05$, Figure 1B).

\section{Nicotine suppresses apoptosis and modulates phosphorylation of p38, JNK and ERK in vitro}

As shown in Figure 1C, nicotine significantly inhibited apoptosis in DOK cells $(P<0.01$; Figure 1C). Nicotine also decreased the expression of $\mathrm{p}-\mathrm{p} 38$ and $\mathrm{p}-\mathrm{JNK}$ and increased expression of p-ERK $1 / 2$ in DOK cells $(P<0.01$; Figure 1D).

\section{Nicotine suppresses apoptosis depending on Prx1 in vitro}

As shown in Figure 2A and 2B, both mRNA and protein expression levels of Prx1 were significantly decreased by Prx 1 Knockdown in DOK cells. Prx 1 knockdown significantly increased cell apoptosis $(P<$ $0.05)$ and expression of p-p38 and p-JNK $(P<0.05)$, and decreased expression of p-ERK1/2 when compared to control cells $(P<0.01$; Figure $2 \mathrm{C}$ and 2D). Nicotine significantly inhibited apoptosis in control cells $(P<$ 0.05 ) but not in Prx1 knocked down cells (Figure 2C). Similarly, nicotine did not exhibit significant effects on phosphorylation of p38, JNK and ERK1/2 in Prx1 knocked down cells (Figure 2D).

\section{Nicotine suppresses apoptosis depending on $\alpha 7 \mathrm{nAChR}$ but not $\alpha 3 \mathrm{nAChR}$ in vitro}

The combination treatment of nicotine and $\alpha$-BTX (a specific inhibitor of $\alpha 7-n A C h R$ ) significantly reduced mRNA and protein expression of $\alpha 7 \mathrm{nAChR}$ when compared to cells treated with nicotine only $(P<0.05$; Figure $3 \mathrm{~A}$ and $3 \mathrm{~B}$ ). In addition, the expression level of Prx 1 was also decreased, which was similar to that observed with $\alpha 7 \mathrm{nAChR}(P<0.05$; Figure $3 \mathrm{~A}$ and $3 \mathrm{~B})$. As shown in Figure 3C, the apoptosis rate was increased in cells treated with nicotine $+\alpha$-BTX when compared to
A

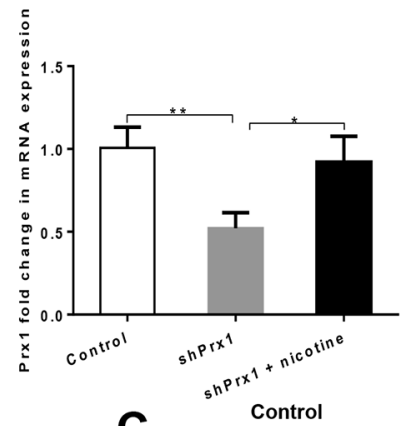

C

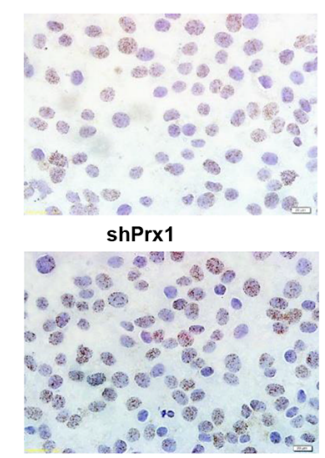

D

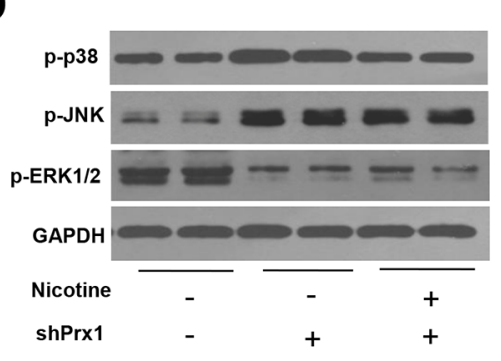

B
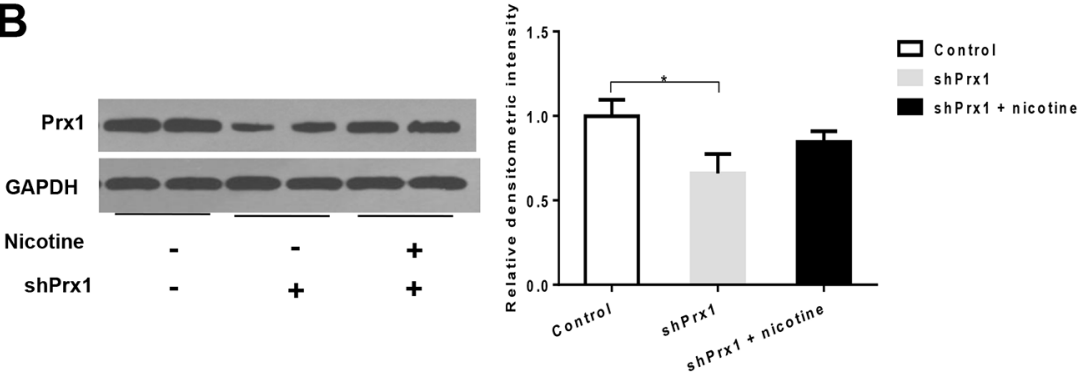

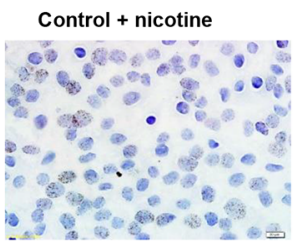

shPrx1 + nicotine
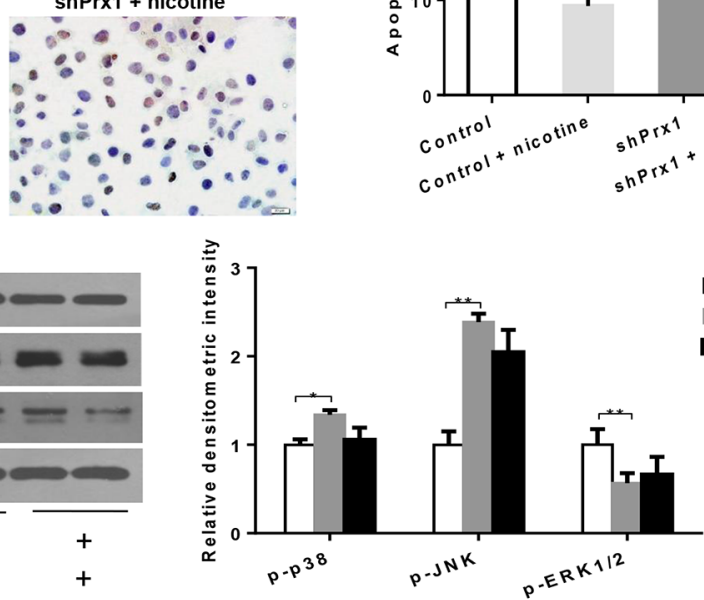

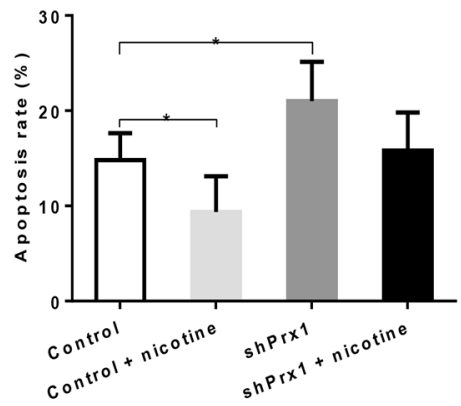

Figure 2: Effects of Prx1 knockdown on Prx1, apoptosis and MAPK in DOK cells. (A) mRNA expression of Prx1; (B) protein expression of Prx1; (C) apoptosis rate detected by TUNEL; and (D) phosphorylation of p38, JNK and ERK1/2. The values are expressed as mean; bars, \pm SE. * $P<0.05$; ** $P<0.01$. 
those treated with nicotine only $(P<0.05)$. The expression of p-p38 and p-JNK was increased and p-ERK1/2 was decreased in cells treated with nicotine $+\alpha$-BTX when compared to those treated with nicotine only (Figure 3D).

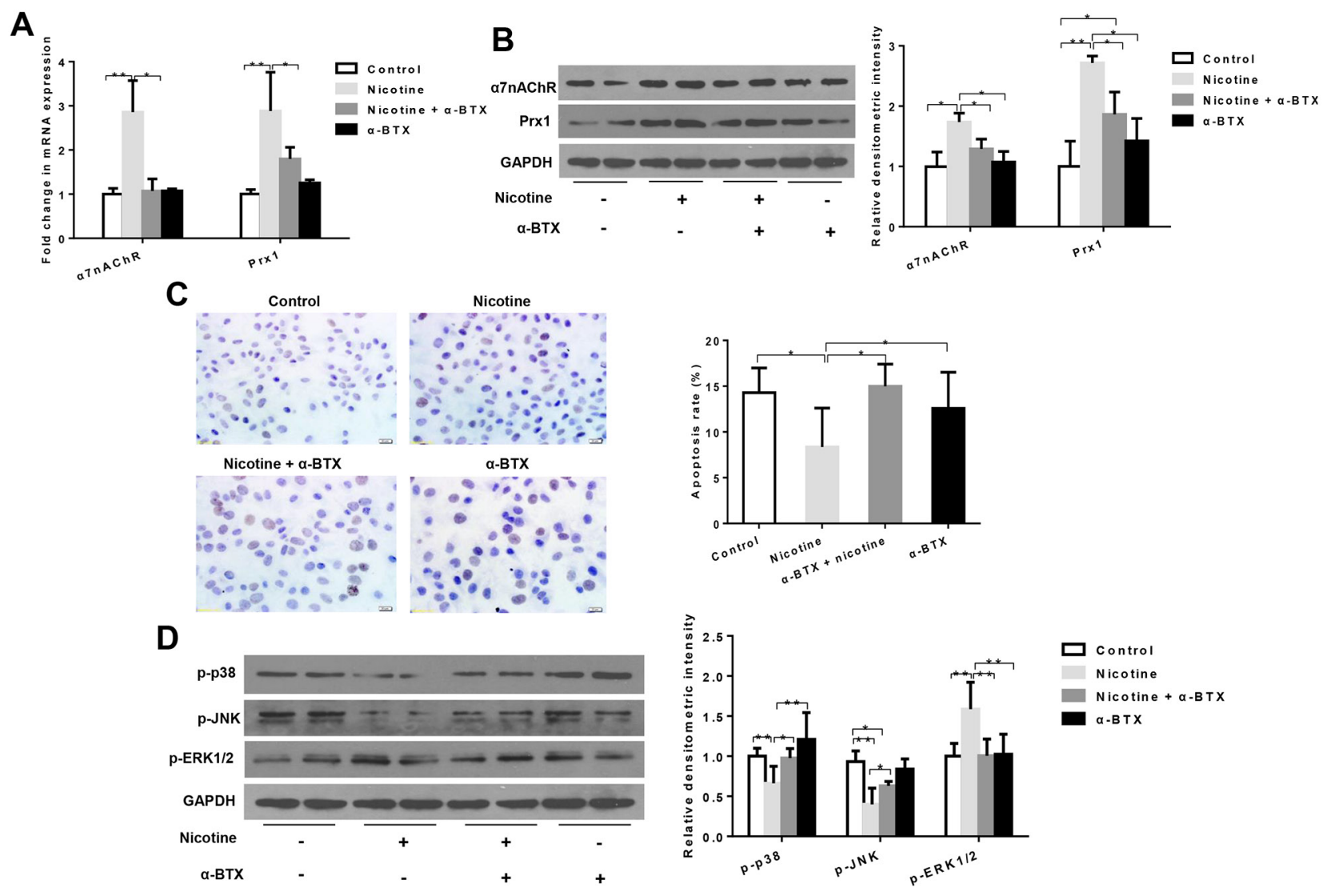

Figure 3: Effects of specific inhibition of $\alpha 7 \mathrm{nAChR}$ on Prx1, apoptosis and MAPK in DOK cells. (A) mRNA expression of $\alpha 7 \mathrm{nAChR}$ and Prx1; (B) protein expression of $\alpha 7 \mathrm{nAChR}$ and Prx 1; (C) apoptosis rate detected by TUNEL; and (D) phosphorylation of p38, JNK and ERK1/2. The values are expressed as mean; bars, \pm SE. $* P<0.05 ; * * P<0.01$.

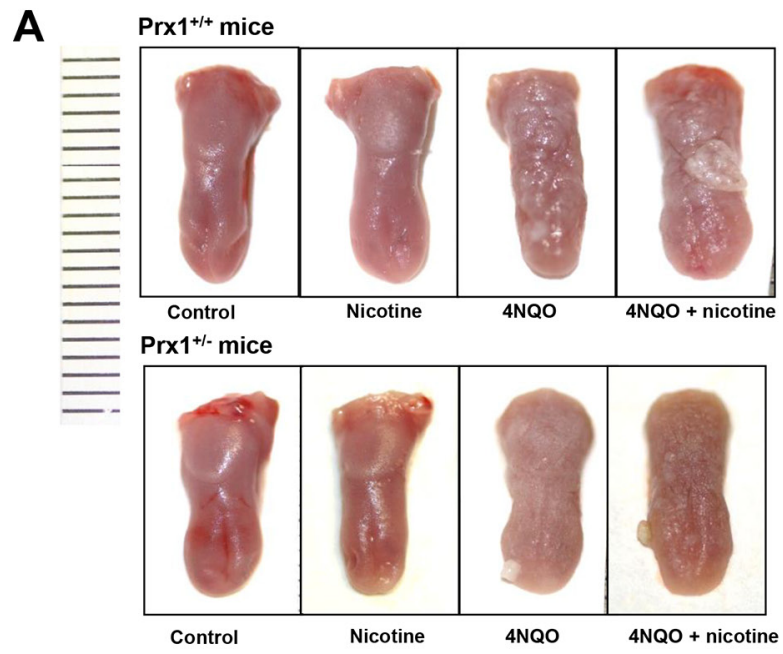

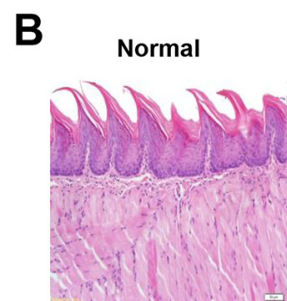
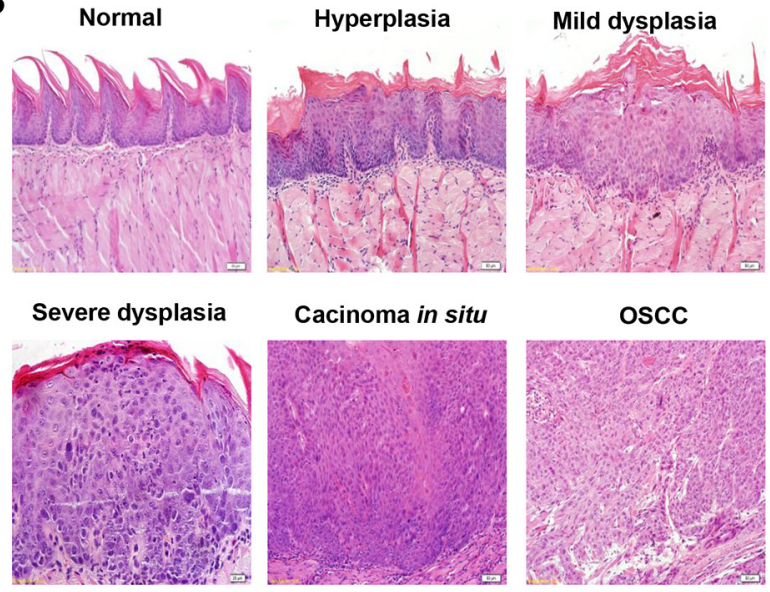

Figure 4: Histopathology of mouse tongue in animals treated with nicotine, 4NQO or ANQO plus nicotine. (A) the representative images of entire tongue collected from Prx1 wild-type and Prx1 knockdown mice; and (B) the representative H\&E staining of mouse tongue including normal, hyperplasia, dysplasia, carcinoma in situ and OSCC (magnification x 200). 
Table 1: Histological evaluation of mouse tongue in animals treated with nicotine, 4NQO or 4NQO plus nicotine

\begin{tabular}{|c|c|c|c|c|c|c|c|c|}
\hline \multirow[t]{2}{*}{ Group } & \multirow[t]{2}{*}{ Treatment } & \multirow{2}{*}{$\begin{array}{c}\text { No. of } \\
\text { animals }\end{array}$} & \multirow[t]{2}{*}{ Normal } & \multirow[t]{2}{*}{ Hyperplasia } & \multicolumn{3}{|c|}{ Dysplasia } & \multirow{2}{*}{$\begin{array}{c}\text { Carcinoma in } \\
\text { situ/OSCC }\end{array}$} \\
\hline & & & & & Mild & Moderate & Severe & \\
\hline 1 & $\operatorname{Prx} 1^{+/+a}$ & 10 & $10(100 \%)$ & & & & & \\
\hline 2 & $\operatorname{Prx} 1^{+/-b}$ & 10 & $10(100 \%)$ & & & & & \\
\hline 3 & $\begin{array}{l}\operatorname{Prx} 1^{+/+}+ \\
\text {nicotine }^{c}\end{array}$ & 20 & $15(75 \%)$ & $5(25 \%)$ & & & & \\
\hline 4 & $\operatorname{Prx} 1^{+/-}+$nicotine & 20 & $18(90 \%)$ & $2(10 \%)$ & & & & \\
\hline 5 & $\mathrm{Prx}^{+/+}+4 \mathrm{NQO}^{d}$ & 20 & & $2(10 \%)$ & $11(55 \%)$ & $2(10 \%)$ & $4(20 \%)$ & $1(5 \%)$ \\
\hline 6 & $\operatorname{Prx}^{+/-}+4 \mathrm{NQO}$ & 20 & & $4(20 \%)$ & $9(45 \%)$ & $6(30 \%)$ & $1(5 \%)$ & \\
\hline 7 & $\begin{array}{l}\text { Prx } 1^{+/+}+4 \mathrm{NQO} \\
+ \text { nicotine }^{e}\end{array}$ & 20 & & $1(5 \%)$ & $6(30 \%)$ & $3(15 \%)$ & $5(25 \%)$ & $5(40 \%)^{f}$ \\
\hline 8 & $\begin{array}{l}\operatorname{Prx} 1^{+/-}+4 \mathrm{NQO} \\
\quad+\text { nicotine }\end{array}$ & 20 & & $3(15 \%)$ & $8(40 \%)$ & $6(30 \%)$ & $2(10 \%)^{g}$ & $1(5 \%)^{g}$ \\
\hline
\end{tabular}

${ }^{a}$ Wild-type C57BL/6 mouse.

${ }^{b}$ Prx1 knockout mouse.

c $5 \%$ nicotine smeared on tongue mucosa, 3 times per week.

${ }^{d} 50 \mu \mathrm{g} / \mathrm{mL}$ 4NQO smeared on tongue mucosa every day.

${ }^{e}$ Nicotine plus 4NQO treatment.

${ }^{f} P<0.05$ compared to Group 5.

${ }^{g} P<0.05$ compared to Group 7 .

Knockdown $\alpha 3 n A C h R$ in DOK cells did not exhibit any effects on Prx1 and apoptosis (Supplementary Figure 1).

\section{NQO induces tongue precancerous lesions in mice}

In $4 \mathrm{NQO}$ or $4 \mathrm{NQO}+$ nicotine - treated animals, the tongues exhibited generally white, thick, rough and visible white patches as well as surface toughness (Figure 4A). Histologically, 4NQO or 4NQO + nicotine-induced epithelial hyperplasia and dysplasia had a thickening keratin layer, similar to OLK histologic features (Figure 4B). We also observed carcinomas in situ and OSCC in animals treated with $4 \mathrm{NQO}$ or $4 \mathrm{NQO}+$ nicotine (Figure 4B).

\section{Nicotine and Prx1 promote the progression of tongue precancerous lesions}

As shown in Table 1, mice treated with nicotine alone (Groups 3 and 4) developed epithelial hyperplasia but no dysplasia or tumors. 4NQO treatment (Groups 5 and 6) induced hyperplasia, dysplasia (mild, moderate and severe) and tumors in mouse tongue mucosa. In wild-type mice, the tumor incidence increased from 5\% in animals treated with $4 \mathrm{NQO}$ only (Group 5) to $40 \%$ in those treated with $4 \mathrm{NQO}+$ nicotine (Group 7; $P<0.05$ ). In animals treated with $4 \mathrm{NQO}+$ nicotine, the incidences of severe dysplasia and tumors were significantly lower in Prx1 knockdown mice (Group 8) compared to wild-type mice (Group 7; $P<0.05$ ).

\section{Nicotine plus 4NQO increases the expression of Prx1, $\alpha 3 \mathrm{nAChR}$ and $\alpha 7 \mathrm{nAChR}$, and induces apoptosis in wild-type mice}

In wild-type mice, the expression levels of Prx1, $\alpha 3 \mathrm{nAChR}$ and $\alpha 7 \mathrm{nAChR}$ were significantly increased in mice treated with $4 \mathrm{NQO}+$ nicotine when compared to those treated with 4NQO only (Figure 5A, 5B and 5C). As shown in Figure 5D, 4NQO and 4NQO + nicotine activated apoptosis when compared to control animals. The animals treated with $4 \mathrm{NQO}+$ nicotine had lower apoptosis rates when compared to those treated with 4NQO only ( $P>0.05$; Figure 5D). Moreover, the expression of Bcl-2 increased in animals treated with $4 \mathrm{NQO}+$ nicotine when compared to those treated with 4NQO only (Figure 5D). In addition, 4NQO + nicotine decreased expression of p-p38 and p-JNK $(P<0.05)$ and increased expression of p-ERK $1 / 2(P=0.77)$ when compared to animals treated with 4NQO alone (Figure 5E). 


\section{Prx1 knockdown increases cell apoptosis in mouse tongue precancerous lesions}

In Prx1 knockdown mice, the expression of Prx1 was significantly reduced compared to wild-type mice $(P<0.05)$ (Figure 6A and 6C). The apoptosis rate was increased and the expression of Bcl-2 was decreased by $4 \mathrm{NQO}$ in Prx1 knockdown mice when compared to wildtype mice $(P<0.05)$ (Figure 6B). The phosphorylation of p38 and JNK was increased and the phosphorylation of ERK1/2 was decreased by 4NQO in Prx1 knockdown mice when compared to wild-type mice (Figure 6C). In Prx1 knockdown mice, no significant difference in apoptosis and the expression of Bcl-2 was observed between $4 \mathrm{NQO}$ only and $4 \mathrm{NQO}+$ nicotine treatments (Figure 6D). In addition, there was no significant difference in phosphorylation of p38 JNK and ERK1/2 between the two treatment groups (Figure 6E).

\section{DISCUSSION}

Prx1 plays an oncogenic role in nicotinerelated oral carcinogenesis. In this study, we found that nicotine inhibited apoptosis by upregulating Prx 1 in oral precancerous lesion cells and 4NQO-induced precancerous lesions in mouse tongue. Nicotine can promote carcinogenesis through its genotoxic effects, facilitating cancer cell growth, apoptosis, metastasis, resistance to therapies, and creating an immune suppressed microenvironment [7]. In this study, we found that nicotine contributes to epithelial precancerous growth, stimulates susceptibility to $4 \mathrm{NQO}$-induced tongue precancerous lesions and accelerates its progression in Prx 1 wildtype mice. However, nicotine alone does not induce precancerous growth. These results demonstrate that nicotine serves as a tumor promoter in the development of oral precancerous lesions in mice exposed to $4 \mathrm{NQO}$.
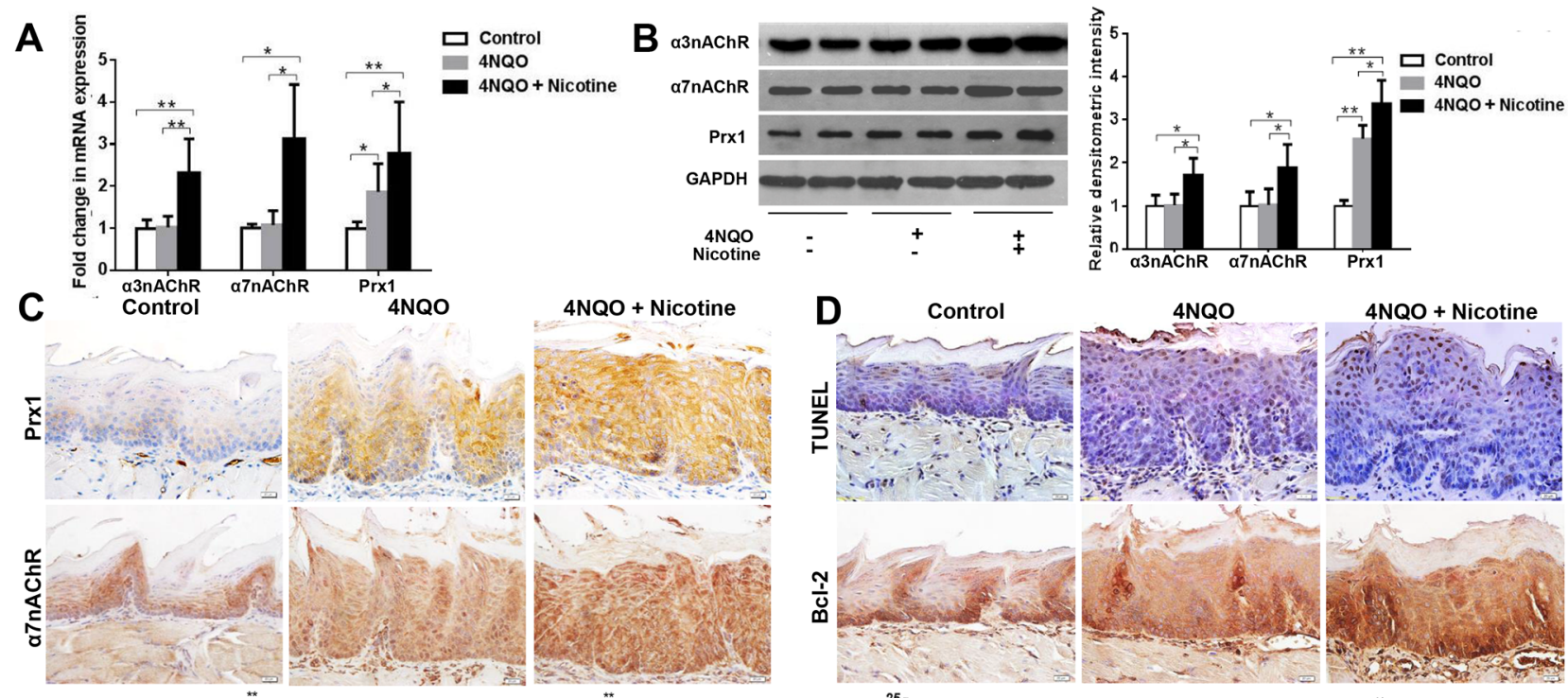

4NQO + Nicotine
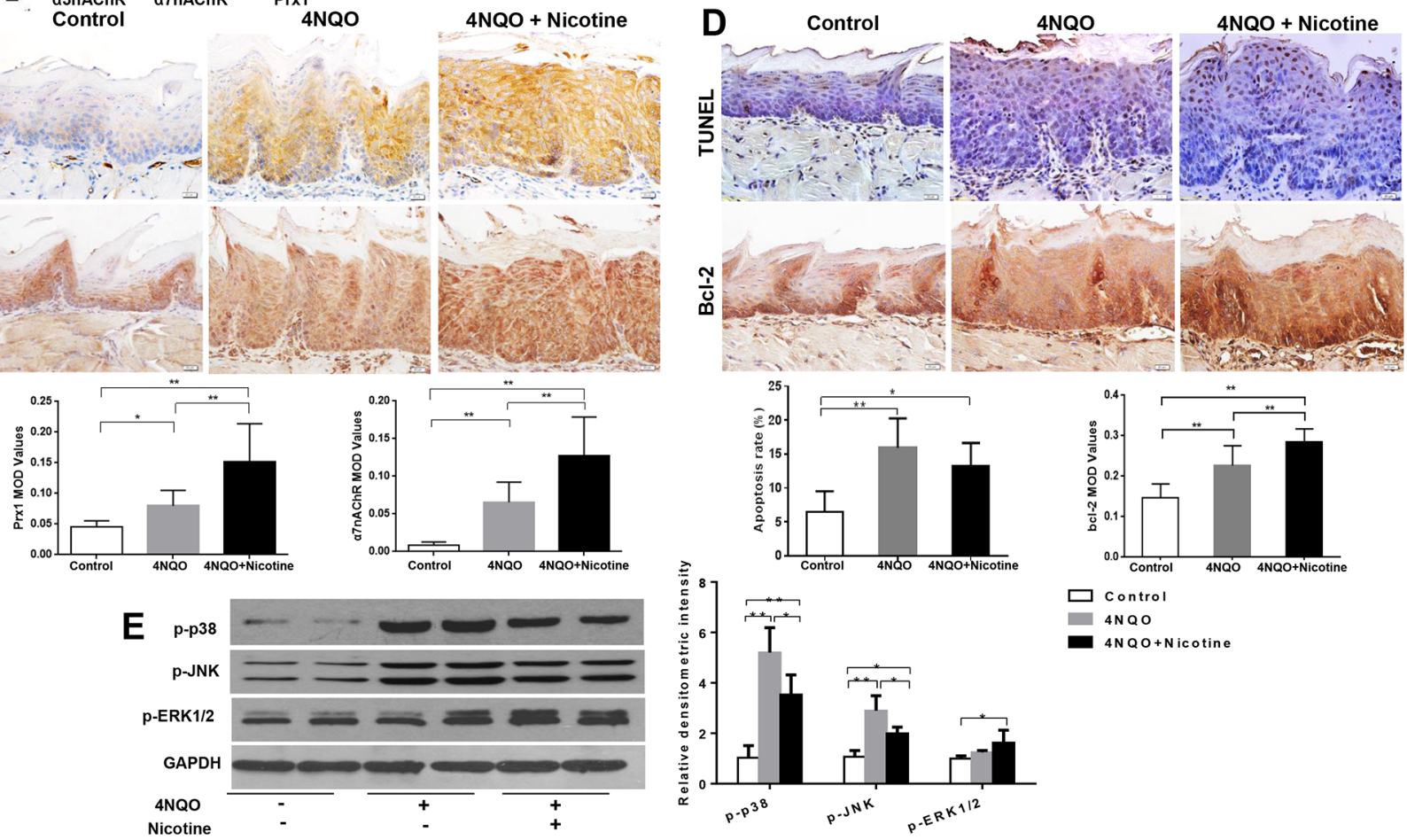

$\square$ control

$4 \mathrm{NQO}$

- $4 \mathrm{NQO}+\mathrm{N}$ icotine

Nicotine

Figure 5: Effects of 4NQO and 4NQO + nicotine on Prx1, $\alpha 3 n A C h R, \alpha 7 n A C h R$, apoptosis and MAPK in Prx1 wildtype $\left(\mathbf{P r x 1}^{+/+}\right)$mice. (A) mRNA expression of $\alpha 3 \mathrm{nAChR}, \alpha 7 \mathrm{nAChR}$ and Prx1; (B) protein expression of $\alpha 3 \mathrm{nAChR}, \alpha 7 \mathrm{nAChR}$ and Prx1; (C) expression of Prx1 and $\alpha 7 \mathrm{nAChR}$ detected by IHC; (D) apoptosis detected by TUNEL and Bcl-2 expression; (E) phosphorylation of p38, JNK and ERK1/2. The values are expressed as mean; bars, \pm SE. $* P<0.05 ; * * P<0.01$. 
Cell apoptosis is a critical cellular event in oral carcinogenesis. Bcl-2 has been identified as a key regulator of apoptosis, which is overly expressed in OLK and oral lichen planus [20, 21]. Apoptosis-related upstream regulators, such as Aurora A, phospho-MEK1/2 and phospho-ERK1/2, are closely correlated with malignant transformation of OLK [22]. One of the tumorpromoting activities of nicotine is to inhibit apoptosis. Our study shows that nicotine significantly inhibits apoptosis in DOK cells and 4NQO-induced tongue precancerous lesions in Prx 1 wild-type mice. Moreover, we found that after Prx1 knockdown, the inhibition of apoptosis by nicotine is attenuated. Prx1 knockdown inhibits precancerous lesion development. The cell apoptosis is increased by Prx1 knockdown both in vivo and in vitro. These results demonstrate that nicotine inhibits apoptosis by upregulating Prx1 in oral precancerous lesions.
Prx 1 is a member of the thiol-specific peroxidases family and plays diverse roles including $\mathrm{H}_{2} \mathrm{O}_{2}$ scavenger, redox signal transducer, molecular chaperone and oncogene [23]. Prx1 regulates several cell biological processes including cell differentiation, proliferation, and apoptosis. Some studies show that Prx 1 protects cancer cells by suppressing oxidative-stress associated apoptosis $[24,25]$. Nicotine can induce oxidative stress and has a positive feedback on regulating Prx1 in OSCC and oral precancerous lesions [26, 27]. In this study, we found that nicotine upregulates $\alpha 3 \mathrm{nAChR}$ and $\alpha 7 \mathrm{nAChR}$ in oral precancerous lesion cells. To further elucidate the association between nAChR and Prx1, we assessed Prx1 and apoptosis after $\alpha 3 \mathrm{nAChR}$ and $\alpha 7 \mathrm{nAChR}$ were blocked respectively. $\alpha$-Neurotoxin, such as $\alpha$-BTX, is a specific inhibitor of $\alpha 7 \mathrm{nAChR}$ and binds tightly to $\alpha 7 \mathrm{nAChR}$ through interacting between $\mathrm{Tyr}^{184}$ and local residues to

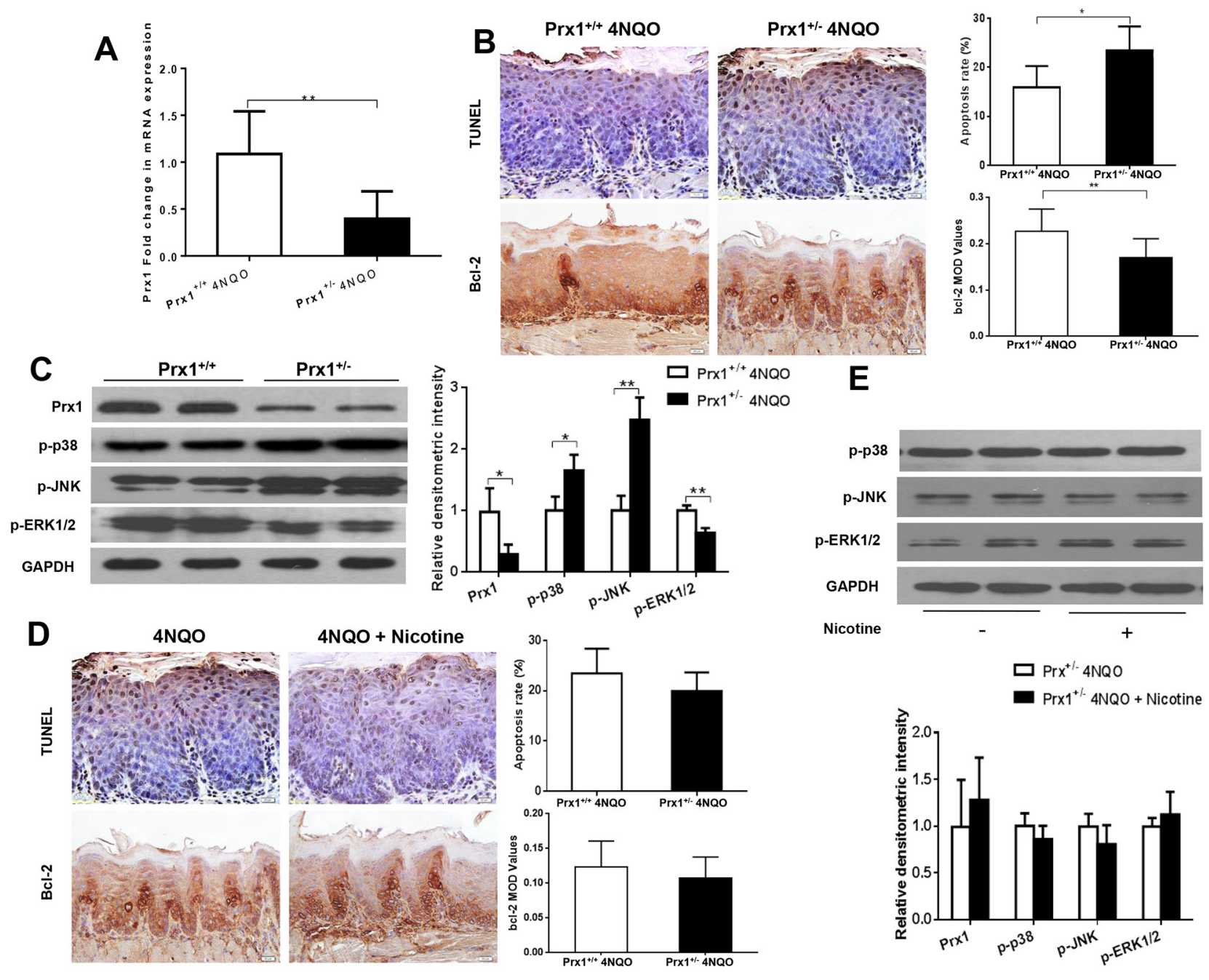

Figure 6: Effects of 4NQO and 4NQO + nicotine on Prx1, apoptosis and MAPK in Prx1 knockdown (Prx1 ${ }^{+-}$) mice. (A) mRNAexpression of Prx1; (B) apoptosis detected by TUNEL and Bcl-2 expression in animals treated with 4NQO; (C) protein expression of Prx1, p-p38, p-JNK and p-ERK1/2 in animals treated with 4NQO; (D) apoptosis detected by TUNEL and Bcl-2 expression in Prx1 knockdown mice treated with 4NQO or 4NQO plus nicotine; and (E) protein expression of Prx1, p-p38, p-JNK and p-ERK1/2 in Prx1 knockdown mice treated with $4 \mathrm{NQO}$ or $4 \mathrm{NQO}$ plus nicotine. The values are expressed as mean; bars, $\pm \mathrm{SE}$. $* P<0.05 ; * * P<0.01$. 
high-affinity subtype-selective $\alpha$-BTX binding. In this study, we also found that $\alpha$-BTX significantly reduces nicotine-induced overexpression of $\alpha 7 \mathrm{nAChR}$ and Prx1, and activates apoptosis. $\alpha 3 \mathrm{nAChR}$ knockdown, however, has little effects on Prx1 and apoptosis.

Nicotine promotes lung carcinogenesis through binding to $\alpha 3, \alpha 5, \beta 4$ and $\alpha 7 \mathrm{nAChR}$ and subsequently activating cell proliferation, apoptosis, angiogenesis and tumor invasion [28]. Activation of cell membrane nAChRs via $\alpha 7$ and $\beta 2$ subunits is associated with increased expression of cyclin D1 and phosphorylation of ERK1/2, inhibition of mPTP opening and resistance to $\mathrm{H}_{2} \mathrm{O}_{2}$-induced apoptosis in oral and lung cancers [15]. Activation of $\alpha 7, \alpha 3, \alpha 4$ and $\alpha 9 \mathrm{nAChR}$ produces growthpromoting and anti-apoptotic signaling that implements the tumor-promoting action of nicotine on lung cells [16]. There are two different pathways involved in cell apoptosis: the extrinsic pathway and the intrinsic pathway [29]. The intrinsic apoptotic pathway is controlled by Bcl2 protein family through mitochondrial outer membrane permeabilization. The Bcl-2 family is composed of about 24 members including cell death suppressors, such as Bcl-2 and cell death inducer, such as Bax [30]. Nicotine increases Bcl-2 expression in breast cancer cell line MCF7 cells [31]. Cytocrome $\mathrm{c}$ is the key component binding to form apoptosome in cytosolic and initiates caspase activation [30]. $\alpha 7 \mathrm{nAChR}$ is expressed on mitochondrial outer membrane. The activation of $\alpha 7 \mathrm{nAChR}$ on mitochondrial can prevent cytochrome c release, thus, blocks intrinsic apoptosis $[32,33]$. In addition, activation of nAChRs can activate p38 MAPK, AKT, RAS/RAF/ MERK/ERK/JAK2 signaling pathways. Theses molecular events are involved in nicotine-promoted carcinogenesis [34-37].

ASK1 is a member of mitogen-activated protein kinase kinase kinase family (MAP3K), also called MAP3K5. ASK1 activates downstream MAPK in response to oxidative stress and induces the cascades of cellular responses including apoptosis, differentiation, cell survival, and production of inflammatory cytokines [38-40]. Numerous studies show that the ASK1/MAPK pathway is involved in tumorigenesis through regulating inflammation, cell proliferation and apoptosis [41, 28]. In our previous study, we found that Prx1 inhibited ASK1induced apoptosis in OLK [19]. However, the association between Prx1 and ASK1's downstream MAPK has not been fully studied. The current study extends the previous pilot investigation through a more rigorous mechanistic study. Our data show that nicotine inhibits apoptosis through upregulation of $\alpha 7 \mathrm{nAChR}$ and Prx1, and suppression of p38 MAPK, JNK and ERK signaling.

In conclusion, this is the first study to elucidate the function of $\mathrm{nAChR} / \operatorname{Prx} 1$ axis in nicotine-related oral precancerous lesions in mice. Our results indicate that nicotine promotes oral precancerous growth through suppression of apoptosis via upregulating $\alpha 7 \mathrm{nAChR}$ and
Prx1. These findings are important because they provide experimental supports that the nAChR/ Prx 1 axis may serve as a new target for treatment of oral OLK and thus, prevent OSCC in humans.

\section{MATERIALS AND METHODS}

\section{Chemicals and reagents}

4NQO, nicotine and $\alpha$-Bungarotoxin ( $\alpha$-BTX) were obtained from Sigma-Aldrich (St. Louis, MO, USA). TRIzol and Lipofectamine ${ }^{\mathrm{TM}} 2000$ were obtained from Invitrogen Life Technologies (Grand Island, NY, USA). cDNA Reverse Transcription Kit and SYBR Green Dye reagent were obtained from Applied Biosystems (Grand Island, NY, USA). Antibodies against Prx 1, $\alpha 3 \mathrm{nAChR}, \alpha 7 \mathrm{nAChR}$ and Bcl-2 were purchased from Abcam (Cambrige, MA, USA); antibodies against p-p38, p-JUN N-terminal kinase (JNK), p-extracellular signal-regulated kinase (ERK) and all secondary antibodies were purchased from Cell signaling Technology (Beverly, MA, USA); antibodies against GAPDH were purchased from Sigma-Aldrich (St. Louis, MO, USA). Enhanced chemiluminescence reagent was purchased from Amersham Biosciences (Pittsburgh, PA, USA). Prx1 shRNA lentivirus plasmid and control shRNA lentivirus plasmid-A were purchased from Suzhou gemma gene (Suzhou, China). $\alpha 3 n A C h R$ shRNA plasmid and control plasmid were purchased from Santa Cruz Biotechnology (Dallas, Texas, USA).

\section{Cell culture and treatment}

The human dysplastic oral keratinocyte (DOK) cell line was provided by Dr. Xiaoxin Chen in North Carolina Central University, USA. DOK cells were maintained in DMEM-High glucose supplemented with $10 \%(\mathrm{v} / \mathrm{v})$ fetal bovine serum (FBS) (Gibco, USA) containing 100 units $/ \mathrm{mL}$ penicillin, and $100 \mu \mathrm{g} / \mathrm{mL}$ streptomycin, in a $5 \% \mathrm{CO}_{2}$ atmosphere at $37{ }^{\circ} \mathrm{C}$. For nicotine treatment, cells received $1 \mu \mathrm{mol} / \mathrm{ml}$ nicotine for 7 days. To inhibit $\alpha 7 \mathrm{nAChR}$ expression, cells were treated with $1 \mathrm{umol} / \mathrm{ml}$ $\alpha$-BTX (a specific inhibitor of $\alpha$ 7-nAChR) plus nicotine. To establish Prx 1 or $\alpha 3 n A C h R$ knockdown cell lines, Prx1 shRNA lentivirus plasmid, control shRNA lentivirus plasmid-A, $\alpha 3 n A C h R$ shRNA plasmid, and control shRNA plasmid-A were respectively transfected to cells using Lipofectamine ${ }^{\mathrm{TM}} 2000$ according to the manufacturer's instructions. After transfection for $48 \mathrm{~h}$, stable transfected cell lines were selected by puromycin $(1 \mathrm{ug} / \mathrm{ml})$ for 10 days. The efficiency of Prx1 shRNA knockdown was determined by RT-PCR and Western Blot analyses. To detect apoptosis, cells were seeded on the glass slide fixed by paraformaldehyde. Apoptosis was examined by using In Situ Cell Death Detection Kit, POD (Roche, Germany) according to the manufacturer's instruction. Finally, the apoptosis rates were detected by Image Pro. 


\section{Animal bioassay}

Wild type C57BL/6 mice were purchased from Vital River Laboratory Animal Technology (Beijing, China). Prx1 knockout mice, 6-8 weeks old, were used in this study [42]. All animals were kept in accordance with institutional guidelines under standard conditions. The experimental protocol was approved by the ethical committee for animal use. The experimental mice were randomly divided into eight groups (Table 1). Wild type mice $\left(\operatorname{Prx} 1^{+++}\right)$in Groups 1, 3, 5 and 7 received the treatment of the vehicle (distilled water; Group 1), 5\% nicotine smeared on tongue mucosa (x3/week; Group 3), $50 \mu \mathrm{g} / \mathrm{mL} 4 \mathrm{NQO}$ (Group 5), or 4NQO + nicotine (Group 7). The Prx1 knockout mice $\left(\operatorname{Prx} 1^{+/}\right)$were randomized into four groups (Groups 2, 4, 6 and 8). At the end of bioassay (16 weeks), mouse tongues were removed after euthanasia and cut in half. One half was immediately stored in liquid nitrogen for future molecular/cellular analysis, and the other half was fixed in formalin to prepare paraffinembedded tissue blocks.

\section{TUNEL staining}

Apoptosis was examined by using In Situ Cell Death Detection Kit, POD (Roche, Germany) according to the manufacturer's instruction. The slides were deparaffinized with histoclear and rehydrated in graded ethanol (100$70 \%$ ). In the cell experiments, cell growing on the glass slide was fixed by paraformaldehyde. The specimens were subjected to PBS washing for 2 times with 5 min each time, and incubation at $37^{\circ} \mathrm{C}$ for $15 \mathrm{~min}$ by proteinase $\mathrm{K}$. Dry specimens were dropped in $50 \mu \mathrm{L}$ of TUNEL reaction mixture, hydrated at light-free condition and incubated at $37{ }^{\circ} \mathrm{C}$ for $60 \mathrm{~min}$. The PBS washed for 3 times with 5 min each time. The dry specimens were then dropped in $50 \mu \mathrm{L}$ of converter-POD and incubated at $37{ }^{\circ} \mathrm{C}$ for 60 min. Freshly prepared DAB solution was used to incubate the specimens for 20 minutes. The apoptosis rates were detected by Image Pro.

\section{Quantitative real-time PCR}

Total RNA was extracted from the mouse tongue tissues or DOK cells using TRIzol according to the manufacturer's instructions. cDNA was synthesized with the High-Capacity cDNA Reverse Transcription Kit. SYBR Green Dye reagent was used to quantify the products formed during the Real-Time PCR reaction. For data analysis, the $2^{-\Delta \Delta \mathrm{Ct}}$ method was used with normalization of raw data to the housekeeping gene GAPDH. The experiments were repeated at least three times. The sequence of primers was: GAPDH-F, 5'-aggtcggtgtgaacggatttg-3',GAPDH-R, 5'-tgtagaccatgtagttgaggtca-3'; $\quad \alpha 3 \mathrm{nAChR}-\mathrm{F}, \quad 5$ '-ggac gggatgtgtggttact-3'; $\alpha 3 n A C h R-R, \quad 5$ '-tggcttctttgatttctg gtg-3'; $\quad \alpha 7 n A C h R-F, \quad 5$ '-aaactcacagatgggcaagg-3';
a7nAChR-R, 5'-ccgtaagcaacacgactgac-3'; Prx1-F, 5'-ggg tattcttcggcagatca-3', Prx1-R, 5'-tccccatgtttgtcagtgaa-3'. In in-vivo experiments, the sequence of primers was: GAPDH-F, 5'-aggtcggtgtgaacggatttg-3', GAPDH-R, 5'-tg tagaccatgagttgaggtca-3'; $\quad$ 33-nAChR-F, $\quad 5$ '-atggaaac caacctgtggct-3', $\alpha 3$-nAChR-R, 5'-aaatccccatcggcgttgtt-3'; $\alpha 7-n A C h R-F, \quad 5$ '-gcaacatctgattccgtgcc-3'; $\quad \alpha 7$-nACh R-R, 5'-tgatcctggtccacttaggc-3'; Prx1-F, 5'-aatgcaaaa attgggtatcctgc-3', Prx1-R, 5'-cgtgggacacacaaaagtaaagt-3'.

\section{Western blot analysis}

Proteins were extracted from mouse tongue tissues or DOK cells with immunoprecipitation assay buffer. Protein concentration was determined using the Lowry method. Equal amounts of protein were separated on $12 \%$ SDS-PAGE gels and blotted onto nitrocellulose membranes. After incubated with primary antibody and horseradish peroxidase-conjugated secondary antibodies, immunoreactive bands were detected with enhanced chemiluminescence reagent. The following antibodies were used: Prx1 (Abcam, USA, 1:1000), $\alpha 3 \mathrm{nAChR}$ (Abcam, USA, 1:500), $\alpha 7$ nAChR (Abcam, USA, 1:1000), p38, p-p38, JNK, p-JNK (CST, USA, 1:1000), ERK1/2, p-ERK1/2 (CST, USA, 1:2000) and GAPDH (Sigma, USA, 1:2000). The experiments were repeated at least three times.

\section{Immunohistochemistry}

Mouse tongue tissues were fixed in $10 \%$ neutral formalin for $24 \mathrm{~h}$, serially sectioned at $4 \mu \mathrm{m}$, and processed for immunohistochemistry. Deparaffinised sections were briefly heated for $10 \mathrm{~min}$ in a pressure cooker containing $10 \mathrm{mM}$ citrate buffer ( $\mathrm{pH}$ 6.0) for antigen retrieval, and followed by $3 \% \mathrm{H}_{2} \mathrm{O}_{2}$ in $0.1 \mathrm{M}$ TBS (pH 7.4) for $15 \mathrm{~min}$ to quench endogenous peroxidases. The sections were then treated with protein block solution (Boshide, China) for 20 min and incubated with anti-Bcl-2 antibody (1:200), Prx 1 (1:50) and $\alpha 7 \mathrm{nAChR}(1: 50)$ overnight at $4^{\circ} \mathrm{C}$. Incubation with primary antibody was followed by incubation with secondary anti-rabbit GT VisionTM polymer (Gene Tech, South San Francisco, California, USA) for 30 min. Finally, slides were treated with chromogen diaminobenzidine (DAB) (Dako, Carpinteria, CA, USA), counterstained with haematoxylin, dehydrated, and mounted for further Olympus BX61 microscope observation (Olympus, Tokyo, Japan). To assess the protein expression in each tongue, five random areas within a section were selected at $200 \mathrm{x} \times$ magnification. The arithmetic mean proportion of positive cells of the five areas represented the protein expression.

\section{Statistical analysis}

Group differences were analyzed for statistical significance by Chi-Square test, ANOVA and t-test. 
Differences were considered statistically significant at $P$ $<0.05$. All $P$ values were two-sided. The analyses were conducted using SPSS 17.0.

\section{Abbreviations}

nAChRs, nicotinic acetylcholine receptors; Prx1, peroxiredoxin 1; OSCC, oral squamous cell carcinoma; 4NQO, 4-nitroquinoline 1-oxide; JNK, JUN N-terminal kinase; ERK, extracellular signal-regulated kinase; MAPK, mitogen-activated protein kinases; OLK, oral leukoplakia; EGF, epidermal growth factor; PI3K, phosphatidylinositol-4,5-bisphosphate 3-kinase; ASK1, apoptosis signal-regulating kinase 1; GAPDH, glyceraldehyde-3-phosphate dehydrogenase; DOK, dysplastic oral keratinocyte; mPTP, mitochondrial permeability transition pore; $\alpha$-BTX, $\alpha$-Bungarotoxin; Bcl-2; B-cell lymphoma 2; MEK, MAPK/ERK kinase; PLC, phospholipase C; PKC, protein kinase C; JAK2, Janus kinase 2.

\section{Author contributions}

C. W., W. N. and H. C. collected data. C.W. and N. S. drafted the manuscript. D.H. analyzed the data. M. Z., L. G., Z. T., and M. Q. assisted with data collection. T. C. and $X$. T. supervised the entire study.

\section{CONFLICTS OF INTEREST}

No potential conflicts of interest were disclosed.

\section{FUNDING}

This work was funded by National Natural Science Foundation of China (81070836, 81470752) and Beijing Natural Science Foundation of China (7152066).

\section{REFERENCES}

1. Siegel R, Ma J, Zou Z, Jemal A. Cancer statistics. CA Cancer J Clin. 2014; 64: 9-29.

2. Warnakulasuriya S. Global epidemiology of oral and oropharyngeal cancer. Oral Oncol. 2009; 45: 309-16.

3. Funk GF, Karnell LH, Robinson RA, Zhen WK, Trask DK, Hoffman HT. Presentation, treatment, and outcome of oral cavity cancer: a National Cancer Data Base report. Head Neck. 2002; 24: 165-80.

4. Amagasa T, Yamashiro M, Uzawa N. Oral premalignant lesions: from a clinical perspective. Int J Clin Oncol. 2011; 16: 5-14.

5. Reichart PA. Primary prevention of mouth carcinoma and oral precancerous conditions. Mund Kiefer Gesichtschir. 2000; 4: 357-64.
6. Grando SA. Connections of nicotine to cancer. Nat Rev Cancer. 2014; 14: 419-29.

7. Xu J, Huang H, Pan C, Zhang B, Liu X, Zhang L. Nicotine inhibits apoptosis induced by cisplatin in human oral cancer cells. Int J Oral Maxillofac Surg. 2007; 36: 739-44.

8. Zhang M, Zhao YH, Tang XF, Hou M. Effect of nicotine on the proliferation and cell apoptosis of oral squamous cell carcinoma SCC15 cells. Zhonghua Kou Qiang Yi Xue Za Zhi. 2012; 47: 233-7.

9. Wessler I, Kirkpatrick CJ. Acetylcholine beyond neurons: the non-neuronal cholinergic system in humans. Br J Pharmacol. 2008; 154:1558-71.

10. Nguyen VT, Hall LL, Gallacher G, Ndoye A, Jolkovsky DL, Webber RJ, Buchli R, Grando SA. Choline acetyltransferase, acetylcholinesterase, and nicotinic acetylcholine receptors of human gingival and esophageal epithelia. J Dent Res. 2000; 79: 939-49.

11. Chernyavsky AI, Shchepotin IB, Galitovkiy V, Grando SA. Mechanisms of tumor-promoting activities of nicotine in lung cancer: synergistic effects of cell membrane and mitochondrial nicotinic acetylcholine receptors. BMC Cancer. 2015; 15: 152.

12. Arredondo J, Nguyen VT, Chernyavsky AI, Jolkovsky DL, Pinkerton KE, Grando SA. A receptor-mediated mechanism of nicotine toxicity in oral keratinocytes. Lab Invest. 2001; 81: 1653-68.

13. Schuller HM. Regulatory role of the $\alpha 7 \mathrm{nAChR}$ in cancer. Curr Drug Targets. 2012; 13: 680-7.

14. Brown KC, Perry HE, Lau JK, Jones DV, Pulliam JF, Thornhill BA, Crabtree CM, Luo H, Chen YC, Dasgupta P. Nicotine induces the up-regulation of the $\alpha 7$-nicotinic receptor ( $\alpha 7-\mathrm{nAChR})$ in human squamous cell lung cancer cells via the Sp1/GATA protein pathway. J Biol Chem. 2013; 288: 33049-59.

15. Chernyavsky AI, Shchepotin IB, Grando SA. Mechanisms of growth-promoting and tumor-protecting effects of epithelial nicotinic acetylcholine receptors. Int Immunopharmacol. 2015; 29: 36-44.

16. Nieh S, Jao SW, Yang CY, Lin YS, Tseng YH, Liu CL, Lee TY, Liu TY, Chu YH, Chen SF. Regulation of tumor progression via the Snail-RKIP signaling pathway by nicotine exposure in head and neck squamous cell carcinoma. Head Neck. 2015; 37: 1712-21.

17. Arredondo J, Chernyavsky AI, Grando SA. Nicotinic receptors mediate tumorigenic action of tobacco-derived nitrosamines on immortalized oral epithelial cells. Cancer Biol Ther. 2006; 5: 511-7.

18. Niu W, Zhang M, Chen H, Wang C, Shi N, Jing X, Ge L, Chen T, Tang X. Peroxiredoxin 1 promotes invasion and migration by regulating epithelial-to-mesenchymal transition during oral carcinogenesis. Oncotarget. 2016; 7: 47042-51. https://doi.org/10.18632/oncotarget.9705.

19. Zhang M, Niu W, Zhang J, Ge L, Yang J, Sun Z, Tang X. Peroxiredoxin 1 suppresses apoptosis via regulation of the 
apoptosis signal-regulating kinase 1 signaling pathway in human oral leukoplakia. Oncol Lett. 2015; 10: 1841-7.

20. Czabotar PE, Lessene G, Strasser A, Adams JM. Control of apoptosis by the BCL-2 protein family: implications for physiology and therapy. Nat Rev Mol Cell Biol. 2014; 15: 49-63.

21. Pigatti FM, Taveira LA, Soares CT. Immunohistochemical expression of Bcl-2 and $\mathrm{Ki}-67$ in oral lichen planus and leukoplakia with different degrees of dysplasia. Int J Dermatol. 2015; 54: 150-5.

22. Dong Y, Li Z, Gao M, Liu C, Liu H, Chen Z, Xiao J. Immunohistochemical detection of aurora $\mathrm{A}$ and ERK pathway in oral leukoplakia and oral squamous cell carcinoma. J Hard Tissue Biol. 2014; 23: 71-6.

23. He T, Banach-Latapy A, Vernis L, Dardalhon M, Chanet $\mathrm{R}$, Huang ME. Peroxiredoxin 1 knockdown potentiates $\beta$-lapachone cytotoxicity through modulation of reactive oxygen species and mitogen-activated protein kinase signals. Carcinogenesis. 2013; 34: 760-9.

24. Kim YJ, Lee WS, Ip C, Chae HZ, Park EM, Park YM. Prx1 suppresses radiation-induced c-Jun NH2-terminal kinase signaling in lung cancer cells through interaction with the glutathione S-transferase Pi/c-Jun NH2-terminal kinase complex. Cancer Res. 2006; 66: 7136-42.

25. Hwang KE, Park DS, Kim YS, Kim BR, Park SN, Lee MK, Park SH, Yoon KH, Jeong ET, Kim HR. Prx1 modulates the chemosensitivity of lung cancer to docetaxel through suppression of FOXO1-induced apoptosis. Int J Oncol. 2013; 43: 72-8.

26. Bhattacharjee A, Prasad SK, Pal S, Maji B, Syamal AK, Mukherjee S. Synergistic protective effect of folic acid and vitamin B12 against nicotine-induced oxidative stress and apoptosis in pancreatic islets of the rat. Pharm Biol. 2016; 54: 433-44.

27. Mei W, Peng Z, Lu M, Liu C, Deng Z, Xiao Y, Liu J, He Y, Yuan Q, Yuan X, Tang D, Yang H, Tao L. Peroxiredoxin 1 inhibits the oxidative stress induced apoptosis in renal tubulointerstitial fibrosis. Nephrology (Carlton). 2015; 20: 832-42.

28. Hayakawa Y, Hirata Y, Nakagawa H, Sakamoto K, Hikiba Y, Kinoshita H, Nakata W, Takahashi R, Tateishi K, Tada M, Akanuma M, Yoshida H, Takeda K, et al. Apoptosis signal-regulating kinase 1 and cyclin D1 compose a positive feedback loop contributing to tumor growth in gastric cancer. Proc Natl Acad Sci U S A. 2011; 108: 780-5.

29. Hyman BT, Yuan J. Apoptotic and non-apoptotic roles of caspases in neuronal physiology and pathophysiology. Nat Rev Neurosci. 2012; 13: 395-406.

30. Martinou JC, Youle RJ. Mitochondria in apoptosis: Bcl-2 family members and mitochondrial dynamics. Dev Cell. 2011; 21: 92-101.

31. Aali N, Motalleb G. The effect of nicotine on the expressions of the $\alpha 7$ nicotinic receptor gene and Bax and
Bcl-2 proteins in the mammary gland epithelial-7 breast cancer cell line and its relationship to drug resistance. Cell Mol Biol Lett. 2015; 20: 948-64.

32. Gergalova G, Lykhmus O, Kalashnyk O, Koval L, Chernyshov V, Kryukova E, Tsetlin V, Komisarenko S, Skok M. Mitochondria express $\alpha 7$ nicotinic acetylcholine receptors to regulate $\mathrm{Ca} 2+$ accumulation and cytochrome $\mathrm{c}$ release: study on isolated mitochondria. PLoS One. 2012; 7: e31361.

33. Kalashnyk OM, Gergalova GL, Komisarenko SV, Skok MV. Intracellular localization of nicotinic acetylcholine receptors in human cell lines. Life Sci. 2012; 9: 1033-7.

34. Carlisle DL, Liu X, Hopkins TM, Swick MC, Dhir R, Siegfried JM. Nicotine activates cell-signaling pathways through muscle-type and neuronal nicotinic acetylcholine receptors in non-small cell lung cancer cells. Pulm Pharmacol Ther. 2007; 20: 629-41.

35. Arredondo J, Chernyavsky AI, Marubio LM, Beaudet AL, Jolkovsky DL, Pinkerton KE, Grando SA. Receptormediated tobacco toxicity: regulation of gene expression through alpha3beta2 nicotinic receptor in oral epithelial cells. Am J Pathol. 2005; 166: 597-613.

36. Arredondo J, Chernyavsky AI, Jolkovsky DL, Pinkerton KE, Grando SA. Receptor-mediated tobacco toxicity: acceleration of sequential expression of alpha5 and alpha7 nicotinic receptor subunits in oral keratinocytes exposed to cigarette smoke. FASEB J. 2008; 22: 1356-68.

37. Shi D, Guo W, Chen W, Fu L, Wang J, Tian Y, Xiao X, Kang T, Huang W, Deng W. Nicotine promotes proliferation of human nasopharyngeal carcinoma cells by regulating $\alpha 7$ AChR, ERK, HIF-1 $\alpha$ and VEGF/PEDF signaling. PLoS One. 2012; 7: e43898.

38. Takeda K, Hatai T, Hamazaki TS, Nishitoh H, Saitoh M, Ichijo H. Apoptosis signal-regulating kinase 1 (ASK1) induces neuronal differentiation and survival of PC12 cells. J Biol Chem. 2000; 275: 9805-13.

39. Tobiume K, Matsuzawa A, Takahashi T, Nishitoh H, Morita K, Takeda K, Minowa O, Miyazono K, Noda T, Ichijo H. ASK1 is required for sustained activations of $\mathrm{JNK} / \mathrm{p} 38$ MAP kinases and apoptosis. EMBO Rep. 2001; 2: 222-8.

40. Sayama K, Hanakawa Y, Shirakata Y, Yamasaki K, Sawada Y, Sun L, Yamanishi K, Ichijo H, Hashimoto K. Apoptosis signal-regulating kinase 1 (ASK1) is an intracellular inducer of keratinocyte differentiation. J Biol Chem. 2001; 276: 999-1004.

41. Hayakawa Y, Hirata Y, Nakagawa H, Sakamoto K, Hikiba Y, Otsuka M, Ijichi H, Ikenoue T, Tateishi K, Akanuma M, Ogura K, Yoshida H, Ichijo H, et al. Apoptosis signal-regulating kinase 1 regulates colitis and colitisassociated tumorigenesis by the innate immune responses. Gastroenterology. 2010; 138: 1055-67.e1-4.

42. Zhang M, Quan XZ, Miao CC, Tang XF. Establishment of Prx1 gene knockout mice. Beijing J Stomatol. 2012; 5. 